\title{
Market-Driven Management and Relations Between Banks and Corporations
}

\author{
Giuseppina Gandini*
}

\begin{abstract}
Many banks, particularly local banks, use standard evaluation systems that often do not allow specific and detailed analysis of the different businesses which, on the contrary, should be encouraged to improve their corporate performance, particularly by trying to demonstrate that they are containing the risk of probable insolvency.

The need to recover a governance structure that is effective for a collaborative relationship with banks entails a review of how organs are composed, and of the appointment, delegation and remuneration system to improve operating effectiveness.

This means paying even greater attention to the corporate culture and the construction of more structured governance models.
\end{abstract}

Keywords: Market-Driven Management; Stakeholders; Banks-Corporations Relations; Insolvency Risks

\section{The Globalisation of Risk and the Approach to Market-Driven Management}

To improve corporate performance and relations with the bank credit market, in an ever changing, unstable global scenario, we have to reflect on: a different approach to intercompany relations; analysis of the tendency for rigidity in the offer of credit by banks; a necessary corporate mindset focused on risk prevention and the instable response to the demand for credit; a redefinition of the operating logics and operating tools necessary to achieve a balance between opportunities for access to bank credit and the offer of funding to companies by banks.

The market-driven approach to corporate management could facilitate intercompany relations when each company identifies the components of value in demand, as in the case of an application for funding to banks, in order to reconcile

${ }^{*}$ Full Professor of Business Administration, University of Brescia (gandini@eco.unibs.it) 
demand and supply, which is very low right now. This basic logic must be associated with a demonstration of the increase in value that can be obtained through the design, production and marketing of goods and services. This added value, when it is achieved by the company, may be transferred to the various categories of stakeholders, including banks (in the form of expenses paid, available liquidity and savings), in order to improve the supply of credit fostering opportunities for economic recovery.

The scarcity of supply that conditions the banking market in its function of granting credit to business, has repercussions on demand which is generally not being satisfied. The banks have a quasi-monopoly in both the offer of finance to business (if we exclude State contributions to businesses in the form of direct financing, or indirectly through the government-subsidised wage compensation fund, tax relief, scrapping, etc.) and the calculation of the price and total of the loans that can be granted.

Governability of the credit offered by banks has been jeopardised recently by the serious crisis that has hit the banking sector and the need to increase the collection and reserve of protected capital. Operational management and risk control, particularly in large international banks and by the watchdog authorities in the countries where the banks operate, are the system's weak point. Serious deficiencies in banks' corporate governance and supervision of links between management of the risks and control related to the market, were the cause of the ongoing crisis that has led to the collapse and salvaging of numerous American and European banks ${ }^{1}$. There can be no doubt that over time banks have developed dynamics to internationalise financial tools that have since proved to be uncontrollable, generating dangerous effects that have triggered a crisis in the entire worldwide economic system. What is more, although banks have adopted governance structures that reflect the complexity of composite groups, they have not proved entirely effective from the viewpoint of the control of corporate governance and the effects produced.

In American banks, the one-tier governance model does not guarantee the full independence and autonomy of the supervisory board, while the external watchdog does not have the power of coercive intervention. In European banks, the coexistence of different models, and the changeover in Italy from a traditional model (horizontal two-tier) to a vertical two-tier model, have created difficulties in terms of shakedown and inter-relations but also controversy regarding appointments, responsibilities and salaries, but above all, limitations and conflict regarding the correct functioning of the control system, demanding regulation by the watchdog authorities. If we combine these problems with the inadequate capitalisation of the banks, in particular local banks, and the reduction in liquidity to offset ever higher risks in a time of global crisis, this explains the significant contraction in the credit available to companies and the stagnation in the economy that slows down recovery even in areas where the closer, more interactive link between smallmedium companies and local banks have limited the consequences of the crisis.

The entrepreneurial system in Italy is conditioned by the contraction in consumption, the fall in demand from foreign markets, the lack of investment and the scarcity of finance both as risk capital but above all as loan capital. Recent measures taken by the government, in Europe and in Italy, have tended to finance 
the banking sector (Tremonti bonds) to increase the capitalisation and liquidity of banks and to help businesses obtain credit and the guarantees that must be offered to both parties and to all stakeholders.

Three basic elements slot into the situation described above, which must be considered if the recovery of the banking sector and business is to be effective: 1) the competitive orientation of the demand and supply of credit to businesses; 2) the transparency of relations in the search for convergence; 3 ) the suitability of the control system.

A competitive orientation to the market focuses on an approach that underpins the philosophy of Market-Driven Management ${ }^{2}$, and envisages, for companies that apply to the banking market:

- the identification of the components of value in demand, to reconcile it with the credit offered by banks, which is usually limited and selective, offering suitable guarantees of economy, effectiveness and efficiency (the resourcesactivities-results-preordained objectives model);

- the demonstration of value creation, through the design, industrialisation and marketing of goods and services that give the company a competitive advantage over its competitors (results-objectives reached better and before competitors);

- the transfer of criteria of differentiated value to banks and other stakeholders in order to create support for the proposed plan and to activate the virtuous circle of consensus related to the distribution of the value obtained and potential access to new resources.

Qualifying corporate management as 'market-driven', even by its recourse to the banks, means acknowledging:

- a cultural dimension, that refers to the understanding and dissemination of standards and values of behaviour (corporate responsibility), according to a corporate vision that is consistent with the complexity of the global markets and relevant competitive contexts ${ }^{3}$;

- an analytical dimension, based on continuous monitoring of the competition system, developing a logic of corporate economics in a state of instability constrained by pull/push corporate communications flows that respect the principle of transparency in order to avoid forms of unfair competition (on both the credit demand and supply sides);

- an operating dimension ${ }^{4}$, which sees time as the key factor of marketing programmes and the related economic-corporate checks (time-based competition), in a logic of corporate management in a state of variable supply, growing demand for credit and competition.

Transparent relations in the quest for a point of convergence implies the need for companies to refocus their attention on the real economy and on the possibility/advisability of identifying the best coordinates to intercept and pilot consumer demand, preparing better, more flexible supply conditions than the competition, to provide adequate guarantees of monetary-financial equilibrium. In other words, companies must show that they have a successful business formula, not only from the viewpoint of their ability to meet demand, to invest in innovation 
and to communicate the equity situation correctly, but also to demonstrate the fairness of the ratio that sees, on one hand, the ability to balance accounts receivables and payables without running out of liquidity even in the presence of losses and, on the other, the request for bank loans linked to the company's competitive sustainability.

The suitability of the control system aims to guarantee the effectiveness of relations. The establishment of a relationship based on trust depends on the guarantees offered by the control system of: safeguarding of corporate equity, respect of conditions of profitability and independence in corporate activities, respect of the law and regulations, and collection and transmission of correct, truthful information.

The qualifying dimensions described represent the conditions necessary to perform an effective process of two-way control designed to guarantee that the expectations of the different stakeholders are met fairly. This means creating the synergies between corporate control systems and communications that the banking sector expects on the economic-financial situation, on internal strategies and policies and on the competitive evolution of the relevant market in a logic of operational benchmarking.

The opportunity to compete effectively on the credit market depends not only on the skills developed for complete understanding of the market itself and on decision-taking based on accurate identification of the perspective risks, but also on the company's willingness to provide the bank interlocutor with information about its operations. In this regard, detailed corporate analysis systems must be prepared, based first and foremost on the dual dimension of:

- historical analysis, regarding information about the company, results achieved, variances from set targets, financial statements and related documents, ratios and financial flows and reports, that characterise past dynamics, and determine the company's current situation;

- perspective analysis, regarding governance purposes and orientation, which generate future developments in terms of manufacturing facilities, product/market combinations, market position and competitive orientation, asset structure, profitability, liquidity and medium/long-term indebtedness, and strengths and weaknesses with respect to present and emerging risks.

Access to comprehensive, truthful information makes it possible to forecast future cash flows, to avoid financial requirements that are not consistent with the financial situation, to plan evolving levels of indebtedness, but also to provide all the detailed information to interact positively with banks, potential suppliers of finance in the form of credit. In fact, transparent relations with banks, while they respect the need for confidentiality, depend on the degree of detail of the analysis.

But also, the availability of information that can give the bank the necessary informative back-up; this speeds up any intervention when financial requirements emerge; it allows the bank to assess the economic goals of investments so as to verify the limits of the loan to grant and/or granted and to avoid possible errors of conduct (overdrafts, lack of cover, investment, etc.).

The establishment of balanced relationships between companies applying for loans and banks assessing the application and the related conditions, therefore 
entails the existence of suitable checking processes on both sides, in view of the partial sharing of the risks. All other conditions being equal, the introduction of monitoring and risk prevention systems by the financed company, should represent a facilitating element.

Correct risk management makes it possible to maintain a relationship of trust with all the stakeholders and this appears obvious in relations with banks, which must assess the company's capacity for risk management in order to grant credit.

In the current context of widespread crisis and unwillingness to grant credit to companies, the attention paid to assessing the potential risks a business must face up to becomes increasingly important. Particularly in periods of contracting economic cycles, exposure to risk increases and banks tend to reduce their support to enterprise, even for investment in promising projects, because of the necessary adjustment of banks' minimum capital requirements. In fact, the probability of having to face insolvency has increased for businesses with the persistence of the crisis and, because the probability of default is one of the most important parameters for rating models, companies must keep a constant check on the dynamics of monetary and credit regulations, and demonstrating that they have suitable tools in place to monitor the perspective conditions of liquidity.

One significant element to assess a company's credit rating by banks, even from the profile of attention to risks, is the adoption of an information and communications system that provides all the quantitative monetary and nonmonetary information, as well as qualitative information that can contribute significantly to a positive rating.

The granting of credit to business depends on both objective factors - mainly related to the parameters imposed by Basel 2, which also sets the minimum equity requirements for banks - and on discretionary factors linked to the perception of the current situation and the risks related to it that may generate excessive prudence on the part of banks in their exposure to risk. In this regard, when assessing the size and value of risk, banks must try to find a balance between the minimum capital endowment and the award of credit to those companies which, from a viewpoint of market driven management, can create opportunities for the economic recovery of the market and represent convenient investments.

Analysis of risk potential for companies entails attributing greater scope for action to the prevention and conscious management of opportunities, reacting proactively to threats.

Careful observation of the critical factors of success, associated both to external variables and to closely inter-related strictly internal elements, makes it possible to identify some risks ${ }^{5}$. These variables are significant for the banks, which focus attention and monitoring activities on them to attribute credit scoring ${ }^{6}$.

External critical factors that must be taken into account regard the positioning of the company in its environment and refer primarily to: the worldwide economic context in which the company operates and the banking system it addresses; the means for the achievement of interactive relations with the various classes of stakeholder, broken down by space and time; the sector or sectors to which they belong as a whole; the selling markets and supply markets of the various manufacturing factors; the interaction with the capital markets and the structure of capital stock. 
External risks are linked to the different composition of the variables mentioned earlier, in relation to phenomena such as: socio-political change and international economic dynamics; ${ }^{7}$ changes to the law and regulations that the company is subject to; the behaviour of the competition in various contexts of negotiation.

The internal critical factors, on the other hand, refer to the strategic, management and financial connotations at an intra-organisational level, and to the related mutual inter-dependence and influence.

The risks linked to the internal variables are primarily:

- strategic risks, related to the development lines chosen to be pursued in time, and the adaptation of strategy to changes in the scenario and to innovative business models;

- managerial risks, related to traditional business, manufacturing technology, operating processes, dealing with changes to processes, product responsibility, etc.;

- financial risks, related to liquidity, tax management, indebtedness, financial speculation, ROI, currency and exchange rates, interest rates, incoming and outgoing payment, the price of raw materials, investment management, etc.;

- information management risks, related to the reliability, availability and suitability of data, IT, the security and confidentiality of information, information fraud, etc.;

- image risks, related to reputation and the brand, and the trust and consensus enjoyed by the firm;

- compliance risks, deriving from the application of standards and regulations, respect of contract commitments, knowledge of legislative changes, etc.;

- environmental and sustainability risks, related to the prevention of environmental damage, the environmental sustainability of a technological innovation, regulations for specific sectors, such as those for companies operating in the energy or biotechnologies fields, etc.

To assess risks correctly and make checks effective, the growth in value must be measured by: defining the activities that generate value; identifying the risks that affect activities; determining ways of managing risk; communicating risk management decisions.

Moreover, understanding of critical factors of success allows a broader vision of the threats and opportunities that emerge from the profitability, corporate and competitive viewpoints (Figure 1).

Critical factors of success are changeable and conditioned by both the relevant economic framework, by related socio-economic changes, by the competitive dimension and the management configuration of each business. However, they are of great managerial significance, because they are an expression of the framework components that are significant for the implementation of corporate governance activities in management processes.

On the basis of these critical factors of success, we can present a brief picture of the principal risks on which a firm should focus its attention and efforts to maintain/increase the value of the company and give adequate guarantees to the banks. 
Strategic risk management ${ }^{8}$ implies necessary coordination with the internal control system, based on a detailed, appropriate model of the characteristics of each firm that is able to:

- preordain current and evolving scenarios;

- avoid the dangers deriving from the evolution of market dynamics;

- tackle challenges with an awareness of the company's current and perspective capabilities;

- stimulate measures designed to generate competitive advantage, trying to limit the oversupply of goods/services by controlling the induced demand of the goods/services produced;

- grasp the favourable conditions offered by the market to develop the specialist supply of the requested goods/services;

- define recourse to credit on the basis of the advantages that derive from the opportunities grasped;

- encourage the offer of credit by the banks on the basis of guarantees deriving from the achievable competitive advantage.

Figure 1: Monitoring Risks in Relations with Banks

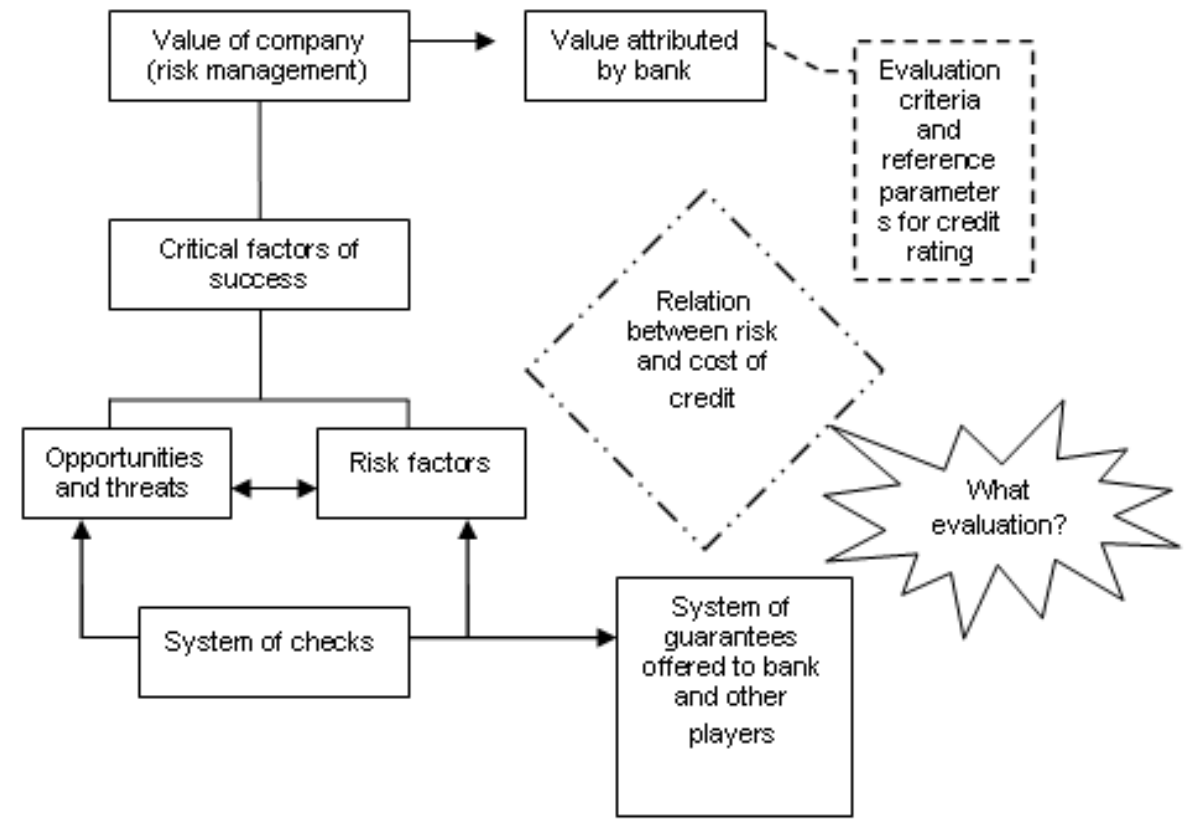

This approach outlines the process to identify, apply and monitor a plan of measures necessary to reduce, or at least to make acceptable, the risks deriving from the running of the company and its positioning on markets that are constantly evolving, but still able to influence the quality information that the banks rely on.

What is more, the control process, designed to manage risks in an integrated way, may be an effective tool to assess the steps taken, the results obtainable and the risk containment guarantees that the bank may refer to. 


\section{Influence of Market-Driven Management on Relations Between Global Companies and the Bank Credit Market}

The logic underpinning market-driven management may be defined in the relationship between businesses and banks, assimilating the position of businesses, with an excessive demand for finance and a high degree of competition between them, to the position of the banks, with a scarce supply of financial means ${ }^{9}$.

The bank credit capital market, reveals that:

- banks, operating in a state of scarce supply, control the capital requested and influence the price of money. The scarcity of liquidity so prevalent in the banking sector today, caused by the drop in savings and the difficulty of repaying borrowed capital, has further reduced the capacity and quality of the credit offered by banks, both by large banking groups that are open to greater risks and having difficulty in evaluating the quality of the credit rating of very different businesses, and by small-medium local banks, with limited equity that tend to address sounder businesses;

- businesses in a situation of over-demand must provide conditions that are necessary and at least sufficient for their credit rating. These objective and subjective conditions may make the difference between competitors when the business is able to face up to the threats and to exploit the opportunities offered by the internal economic-manufacturing situation and by the external environment to create a competitive advantage with respect to competitors on the market and in relation to banks.

The current situation in the banking sector identifies a supply that remains scarce, which, due to a lack of alternative products, has created indirect competition through the supply of substitute financial products, the so-called 'derivates', which have made it possible to offer credit by transferring the debt (subscribed share) from one party to another, and resulting, in the long term, in a crisis in the credit brokerage system ${ }^{10}$. The collapse of the network of relations between businesses and banks, with the failure of many banking institutes and numerous industrial companies, has aggravated the position of businesses applying for loans from banks. Since the banking system cannot and must not abandon the possibility of development linked to investments in businesses through the negotiation of credit capital, to stimulate and induce the offer of credit by banks, companies must show that they deserve the loans and are capable of achieving satisfactory results. The positive results achieved by businesses will enable the financing banks to encourage the trust necessary to obtain new capital, to collect the larger savings achieved by the various social agents (company employees who are savers themselves and can become investors, businesses with surplus liquidity, the State that guarantees the loans necessary for the country's economic development, etc.), to increase and improve their results, particular in the long term.

To win competitive advantage, a business must make proactive its analysis of the demand from other businesses, improving the parameters that evaluate the sustainable value generated in relation to the quality of the business relations established. In particular, the reputation and value of every company's social 
capital $^{11}$ are two important elements for the management of critical resources like access to credit.

The possibility of demonstrating the long-term sustainability of the value of a business depends on its capacity to communicate to all partners the formative and informative credibility of relations, the motivations and positive effects produced by governance activities on the profitability of capital and on the corporate appreciation deriving from the results achieved.

Suitably addressing requests for finance and boosting the supply of equity guarantees, reputation and risk control to minimise/eliminate the possibility of insolvency makes it possible to reduce the imbalance between the demand and supply of credit (Figure 2).

Figure 2: Relationship Between Demand and Supply in Recourse to the Credit Market

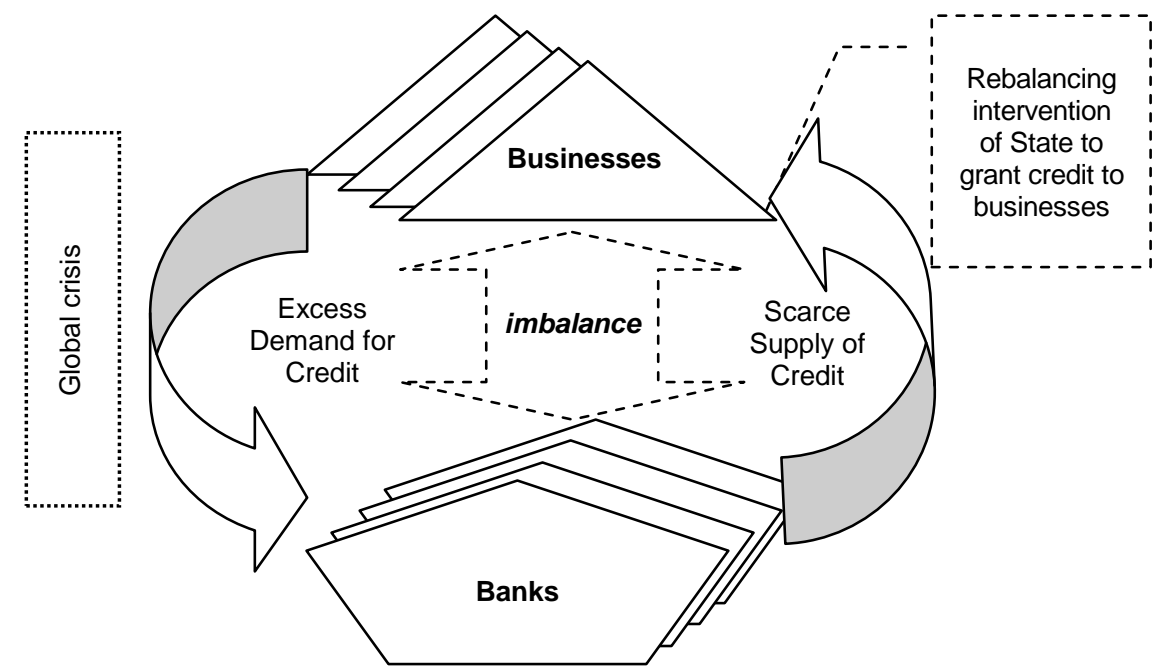

Careful observation of the distinctive characteristics linked to the reputation and asset structure in view of future sustainability, entails distinguishing between different categories of businesses, which can initially be divided into:

- organisations that are relatively sound from a technical-manufacturing, financial and market viewpoint;

- weaker organisations from the viewpoint of credit and capital loans but with excellent potential for technical-manufacturing innovation;

- small independent organisations in a position of sub-supplier to larger public and private companies, whose managerial characteristics often determine a lack of liquidity and under-capitalisation.

The company's ability to exploit its reputation as a strategic resource that is difficult for competitors to imitate, appreciated by stakeholders in business relations on the basis of an adequate social capital, makes it possible to develop activities with a high added value, to reduce transaction costs, to obtain competitive advantage offering quality guarantees, and to increase the possibility of strategic alliances with other partners. To this we must add the need to know and be known, 
therefore to give correct information about the guarantees offered even with reference to the implications of adopting a stakeholders engagement approach, ${ }^{12}$ which in many cases can help small businesses to create the alliances necessary to give competitive force to their applications for credit.

Businesses that intend to maximise their potential to maintain conditions of profitability, are obliged to analyse and assess:

- their financial situation in relation to that of competitors;

- the offer of loans or financial instruments made available by banks, and the basic conditions that regulate the granting of credit to businesses;

- the significant variables that affect the soundness of the financing entity;

- the transparency of behaviour;

- the consistency between guarantees requested and credit supplied;

- the negotiating power that may characterise the bargaining, and the possible margin for manoeuvre on the basis of the equity, profitability and financial guarantees available;

- the alternative counter-offer with respect to the conditions requested by the bank and offered by competitors.

The constant scarcity of resources compared to requests and the current crisis on the credit market, which is extremely exposed to constraints, risks and global conditioning, underlines that: the appreciation of the quality of credit grantable is conditioned by the limited competitive interdependence of the banking sector; the capacity for control reveals a scope of intervention that is limited purely to the local credit market which allows banks to propose limited alternatives for access to credit and puts companies in a position from which it is difficult to negotiate. As a result, the intervention of investment banks or commercial banks in support of specific business sectors ${ }^{13}$, draws attention to the problem of hedging risks and the factors they derive from, which include the risk of the quality of the finance offered. However, even these cases only partially solve the demand for credit, because they increase the total risks that businesses have to face.

What is more, analysing the communications and governance implications linked to the latest attempts by a number of banks to diversify their business, has not occasionally entailed the implementation of co-makership relationships, in an attempt to resolve, in some cases and in this way, the imbalance between credit supply and demand. This was evident in the cases in which credit was granted through inter-bank relations or following the acquisition of capital shares or investments in stock in the bank's portfolio by the company that was offered an advantageous, but not always safe, differential between the creditor interest rate and the debtor rate.

Financial operations are an important component of the success of any business. Businesses must strive constantly to maintain the optimal conditions of consistency between the need for additional financial means, for which they apply to the banking market, and the financial situation, i.e. the capacity to obtain these resources economically. As a result, successful companies need information, evaluation and monitoring systems that are able to: anticipate monetary dynamics and related financial requirements; optimise the financial control of current operating activities and supplement the profitability and monetary-financial 
objectives; understand market alternatives, factors of dynamisms and related risks; monitor the conditions for the potential provision of credit and relative consistency with the capacity to repay it and to pay the interest, at conditions that do not destabilise the balance between profit and equity. In the current market situation, it is essential to deal with the issue of risk management in advance.

To establish high profile relationships in a market as competitive as that of bank credit, one must show that one is able to achieve a better performance than one's competitors that will meet the requirements considered significant by the financier.

A firm's capabilities must be judged with reference to other competitors in the same sector or the competitive alternative. In this regard, it is essential to work on the critical variables mentioned above: reputation, social capital, corporate governance structure, internal control system, information and communications system, all designed to identify the risks facing the firm and the bank. Maintaining a substantial balance in the governance of critical factors of success and of the internal and external variables that influence them, depends on the ability to identify, supplement and correlate significant parameters-objectives that reflect these variables.

The main difficulties of acting on critical variables to meet parameters-objectives that are envisaged and/or required by banks, regard SMEs in particular, which are generally affected by under-capitalisation, a significant impact on demand because of economic crises and governance models ${ }^{14}$ focused on the concentration of ownership, management and control. Successive investigations have shown that in approximately $13 \%$ of SMEs set up as joint-stock companies, by far the most widespread legal form is the S.r.l. (limited responsibility company) for which a Board of Auditors is not obligatory. What is more, a sample inquiry has shown that management control is performed in just over $50 \%$ of the companies, while the watchdog function demanded by Leg. Decree 231/2001, is performed primarily by the owners, which results in a significant overlapping of different responsibilities that do not offer the outside world sufficient guarantees of correct risk management ${ }^{15}$.

Any SMEs, even those in associations, wishing to operate with a market driven management logic to access credit before and better than their competitors, should: overcome an aversion to the delegation of power; develop a system of independent checks to analyse and contain risk; expand their long-term strategic vision and envisage a dimensional development plan to exploit the requested loans; provide performance indices that reflect a high added value and containment/better exploitation of scarce resources.

The use of significant qualitative-quantitative parameters to measure results and the degree of achievement of set goals can stimulate a smaller company to compare and refine the tools that can improve reliability, and thus the rating, when applying for credit from the bank. 


\section{Governance Responsibilities, Control Systems and Rating Culture in Businesses}

The crisis currently affecting banks and businesses in spite of the reform of the regulation and supervision framework in Europe that safeguards the banking sector and is also trying to encourage intervention in favour of small and medium enterprise (SMEs) in particular, is due to a large extent to the changing operational approach where the granting of credit is concerned.

As things stand, many banks, particularly local banks, use standard evaluation systems that often do not allow specific and detailed analysis of the different businesses which, on the contrary, should be encouraged to improve their corporate performance, particularly by trying to demonstrate that they are containing the risk of probable insolvency. The variables that contribute to the scoring include the probability of default which calls for targeted intervention by the company that must define its governance policies in terms of: governance structure, asset structure, financial capability, income trends, balance sheet and remuneration policies and transparent communications.

The need to recover a governance structure that is effective for a collaborative relationship with banks entails a review of how organs are composed, and of the appointment, delegation and remuneration system to improve operating effectiveness. Very active and efficient firms must assess the option of recapitalising the company, restructuring debt, monitoring/reviewing the incoming and outgoing payments cycle, improving the financial planning processes, reorganising manufacturing processes and personnel training, improving the IT system, drafting more detailed information, striving to create targeted, lasting relationships with chosen bank intermediaries that appreciate the quality of the rating of the company offered in a market-driven logic, which can also urge banks to find a point of convergence with virtuous businesses.

Market dynamics have determined significant consequences for smaller businesses, many of which have had to adapt to the requests from credit brokers, by trying to pursue measures designed to exploit the competition between banks, particularly where they are most numerous; by appealing to multiple credit lines; by seeking contacts with non-banking intermediaries: by recourse to riskier businesses at or beyond the limits of illegality; adopting self-financing and appropriation policies ${ }^{16}$.

Obviously, being in a position to repay the loans received and to pay the interest agreed at the set deadlines, or possessing the capacity to capitalise while maintaining a required level of solvency, means maintaining a condition that is necessary but not sufficient in the long term unless it is grounded in an awareness of the emerging problems and of competitive changes in the surrounding environment. This may entail inefficient use of resources which foreshadows the inability to orient the company's growth on the basis not only of the size of the loan granted, but also the chosen technical forms and the breadth of the services offered, and on maintaining low interest rates and achieving better conditions.

This means paying even greater attention to the corporate culture and the construction of more structured governance models, with organisational forms that are more suited to the ramification of the functions and to the implementation of 
activities that add value and guarantee better credit access conditions and stronger growth.

The governance system adopted is linked to the type of controls implemented by the company, which indicate a choice of direction, benchmarking and checking that must be able to trigger a process of internal self-evaluation capable of supplying sufficient guarantees for the credit rating and above all of stimulating a cooperative relationship that can overcome any conflict with banks. It is therefore crucial to provide information that is increasingly truthful, clear and transparent, and to develop policies to improve the rating, taking into consideration the evaluation parameters adopted by the banks.

Banks have increasingly sophisticated rating systems, which can provide evaluation references for all types of loans and all businesses, on the basis of which the credit and negotiation conditions are defined, also depending on the client's characteristics and his capacity to repay. Firms that have recourse to bank credit, to establish lasting relations of trust and consensus with banks, must pay great attention to evaluation conditions, which can be associated with the usual parameters that are the target of an effective internal control system. In this sense, companies that already have complex internal control systems must check whether the control parameters and indices adopted at management level, offer all the references necessary to constantly monitor the variables that can influence the decision to grant credit. Business that adopt simplified systems, on the other hand, will find useful references in the rating system to check that all the critical factors of success are taken suitable advantage of in the context of internal controls, in other words to review and supplement the variables to be monitored.

In this situation, the rating culture must be disseminated in businesses, particularly the smaller ones that often tend to favour certain more crucial factors over others. In fact, businesses with a positive competitive orientation to the credit market should share with banks a rating system that starts from a check-up of the firm's state of health and goes on to propose and compare this with the rating established by the bank.

The above considerations acquire specific importance for SMEs, which must see the rating culture as an opportunity, in reference to behaviour that is not limited to passive respect of the standards and requests of the banks, but exploits every opportunity to remodel their status and to plan their future development. A critical factor of success to improve access to credit for small and medium enterprises could be the development of the degree of control, both inside and outside the organisation, to achieve/measure sustainable added value which, in line with the required parameters, demonstrates the quality of the rating and creates competitive advantage in recourse to credit.

The European Commission intervened as early as 2005, turning its attention, in particular, to relations with SMEs, and providing a practical guide for recourse to bank loans, in order to base the relationship on more transparent information and shared programming of the targets to be reached, according to a number of suggestions that are summed up in precise recommendations ${ }^{17}$. Since then, more attention is being paid to the system to check and evaluate the risks that should feed and spread the culture of rating quality in businesses for access to bank credit (Figure 3). 
The European guidelines set down specific rules which, in the light of the considerations so far, should induce companies to:

- activate and consolidate an information circuit with banks regarding the credit rating evaluation system, distinguishing between the rating systems applied by each bank, the award processes and the documentation requested and, at the same time, to verify the plans, action programmes and accounting documents that make it possible to reduce any asymmetry in the information in the mutual interest;

- prepare the necessary, clear, comprehensive and correct documentation that is more than sufficient to provide suitable, responsible and updated information in time;

- stimulate and observe the best credit offer conditions by banks, even with respect to competitive companies in terms of the demand for credit;

- negotiate the contract conditions and the price of the loan, giving punctual replies and offering better guarantees;

- intervene proactively on the rating, acting in advance and monitoring the trend of the main factors that influence it in order to check and improve the risk profile;

- evaluate the progress of the loan and the effects on the conditions applied, also considering the rating as a constantly updated procedure, together with suitable, responsible attitudes to the set rules, payments and possible changes in the benchmark sector that may modify relations with the bank;

- check the possibility of reducing recourse to loans from banks;

- find alternative proposals to limit the credit requirements as in the case of resource to leasing, factoring and warehouse optimisation, or by exploring possible alternatives that may regard different forms of financing, such as public or intermediate finance or even trying to attract new capital.

Figure 3: Business Behaviour Lines

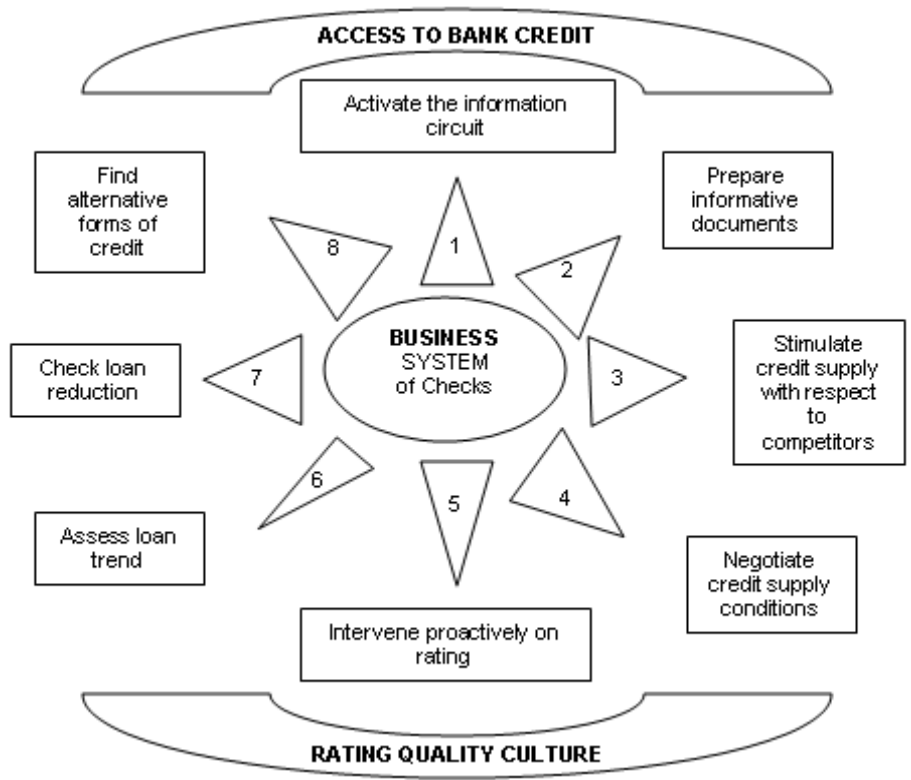


Credit consortia play an important role in the brokerage relationship between banks and businesses, and their goal is to act mutually to provide a collective guarantee of credit lines in favour of partners or associated companies. These consortia can be seen as a tool to mitigate the risk for the banks but also as a tool to simplify access to credit, in particular for small and medium enterprises ${ }^{18}$. Persuading companies to embrace the rating culture means understanding the fundamental principles and techniques with which the bank will assess the risk linked to the decision whether or not to grant a loan. This is backed up by the importance of a company's process of self-assessment, not only to improve relations with the bank, but also to develop opportunities for growth and awareness of present and future possibilities.

\section{Global System and Competitive Market Orientation to the Bank Credit Market}

The protection of the stakeholders and satisfaction of the related expectations, although expressed and attributed differently if they refer to a company rather than to a bank, depends on the responsibility taken on by each of the two corporate structures and the resulting relationships.

The fallout of the contacts between the company and the bank in relation to stakeholders takes shape in terms of the parties' global responsibility that emerges from the combination of the economic, administrative, social and environmental aspects ${ }^{19}$.

The system of relationships and checks that underpins the bond between businesses and the banking system is multidirectional, affecting not only corporate (stockholders, board of directors, board of auditors) and non-corporate parties (control boards, watchdog organism, managers, employees), economic stakeholders in each of the two types of enterprise, but also external parties that are economic and non-economic stakeholders, such as suppliers, customers, investors, savers, competitors, financial and public authorities, the general public, the environment, etc.. This is all the more evident when, at times of crisis, we look for solutions that involve all stakeholders and meet everyone's expectations better. There has been a shift in this direction in the search for ways of granting credit to businesses without damaging the banks, but rather by encouraging investments between banks that could have the resources necessary to finance enterprise. Among the latter, the proposal that envisages the sale of shares in Banca d'Italia, currently held by other banks and entities, to the Central Bank itself, which could thus place them with numerous institutional investors, giving new equity resources to both larger and smaller banks. The latter could benefit indirectly if the listed banks undertook to subscribe new capital necessary to capitalise smaller banks and to promote the grant of credit to businesses.

Businesses and banks must reconcile the opportunity for growth on the basis of the capacity to create value and of efficiency and productivity targets, with the general interests of the continuity of the company and of work, of protecting savings and the capacity for consumption and investment, as well as of supporting to the development of the local, national and global communities. Naturally the 
behaviour adopted, at all levels, by operators of the companies and banks must be founded on respect of the principles of responsibility, competence, correctness, honesty, equity, transparency, effectiveness and efficiency, without forgetting to assess the effects produced in terms of healthy, prudent management that characterises the behaviour of the banks specifically. This means that companies must focus on implementing control and comparative evaluation instruments and on the effectiveness of social communications (qualitative-quantitative, mandatory and voluntary) able to demonstrate to banks that they deserve stakeholders' trust.

Combining the responsibility of the conventional business with the bank's responsibility means combining the primary goal of maintaining conditions of economic balance, guarantee remunerated work and capital, with the common and unavoidable objective of safeguarding the expectations of other parties and maintaining future sustainability. The significant players in the economic system in which banks and businesses operate, are those who can obtain advantages or have expectations from both types of business (Figure 4).

Global responsibility ${ }^{20}$ considers all classes of significant stakeholders in relation to the mechanism of mutual influence that tends to magnify the variables that influence the exercise of responsibility; the responsibility observed from a strictly economic-business viewpoint assimilates the inter-connection between the company and the chosen significant player, the bank in this case, and the relations/consequences that regard other parties.

The business that distinguishes between significant players, a bank for example, based on the relations linked to the development of core activities and governance of the business, may choose to determine the degree of influence on the granting of financial resources as risk capital, credit or investment, however it must also assess the fallout in economic, social, competitive and environmental terms for other social players.

Figure 4: The Osmotic Relationship Between Businesses and Banks and Global Responsibility to Stakeholders

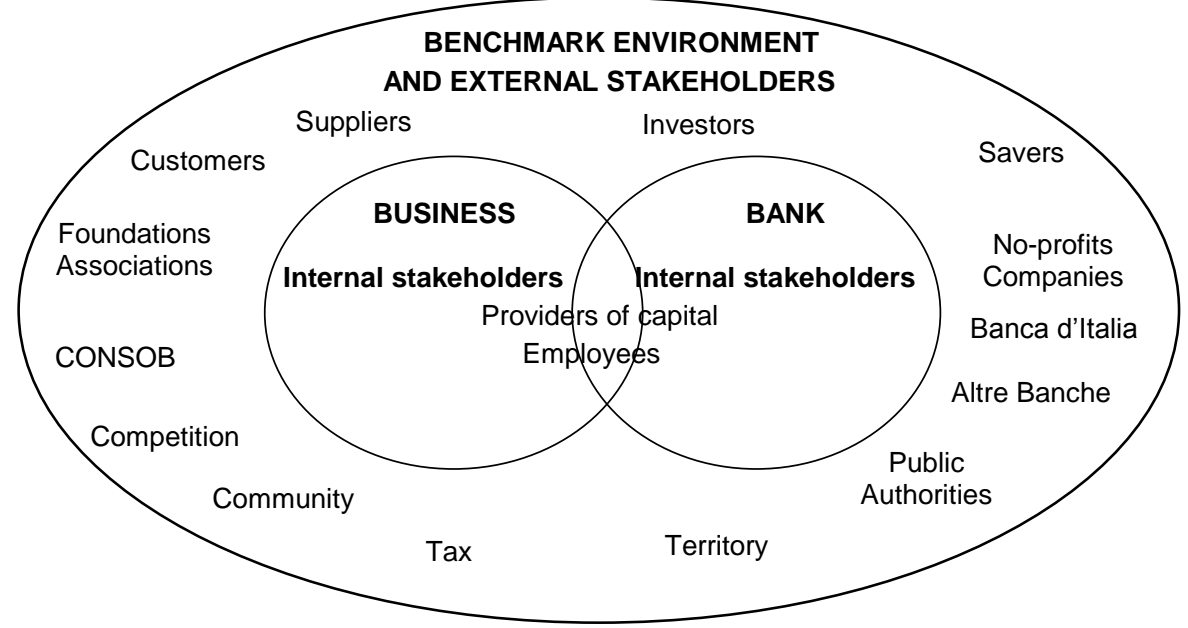

Numerous relationships are established between businesses and banks; they may be direct and internal (with participation in governance), indirect and external 
(grant of loans or little participation), or even based on co-makership or brokerage when it is a question of selecting privileged relationships with partial sharing of responsibility (financing for project, finalised investment, etc.). Each type of relationship entails responsibilities and risks for the businesses linked to choices of competitive orientation, designed to obtain an advantage over competitors in the credit market (greater resources, before others, at lower costs). The outcome of these decisions is additional responsibilities and risks related to the repercussions it can have in relation to all the other internal and external stakeholders.

For a company, operating in conditions of economic viability and durability means adopting behaviour designed to reconcile all the legitimate expectations that meet in it fairly, based on the assumption of responsibility within the bounds of legality, maintaining conditions of balance, meeting the expectations of the local community and respecting the ecosystem. The adoption of responsible behaviour that embraces effectiveness, efficiency and productivity is however reflected in the capacity to transfer strategies of correct governance to the entire organisation, in full respect of competence at different decision-making/operational levels.

That is not all; if businesses wish to strive for competitive success and to maintain the aforesaid conditions, they must invest in innovation and unexpressed demand to limit the supply of goods and services (generally in excess) to the market potential, trying to satisfy the consumers' renewed/modified expectations. Application of the logic of market-driven management can help businesses both to achieve their primary goal of output subordinated to sales and the related goal of the application and striving for the best possible conditions of access to bank credit.

Combining the two objectives means that both parties must embrace widespread values designed to suitably link the prerogatives of the economic, social and competitive dimension with the adoption of control systems, that are complex and ramified, designed to guarantee the correct implementation of the strategies selected, minimising risks and optimising results. The value of businesses does not depend exclusively on the economic relationships established between different companies and social groups, or on the positive or negative fallout for other parties, but is also linked to the commitment expressed in other relationships from which consensus and new resources may emerge.

Corporate management therefore produces effects that go beyond the achievement of profits and are amplified by future sustainability, the economic development of the relevant country and market, and the legislative and political impact. In this regard, we must carefully assess the risks, damages and benefits of the institutional goals that influence the environment, the many classes of stakeholder and the means for the development or survival of collateral economies. This means that the corporate goals also extend to other related or consequent purposes, all designed to create or add economic, but also competitive, social and environmental utility.

Improving the corporate results and the global effectiveness calls for: suitable interaction with all internal and external stakeholders; enhanced relations between economic, competitive and social components in a unitary strategic framework; clear, transparent communication of the principal phenomena that characterise the proposal in the various areas of interaction. 
To measure the improvements achievable will demand feedback of the effects produced by company activities in the economic, social, political and territorial context. In addition, it will require understanding of the related responsibilities and direct attribution of the same to the governance organs whose task it is to organise resources, to guide operations and to pursue results able to meet stakeholders' needs.

However, recognising responsibilities is not the same as meeting them; they need to be taken on board effectively by the governance and management organs during the performance of their activities and constantly monitored by the internal control system, on a par with any other management element ${ }^{21}$.

Similarly, for a bank, operating in line with social responsibility means taking an interest that goes beyond productivity and profit regarding stakeholders directly linked to the firm's activities as such and as a bank. In this sense, the bank takes the responsibilities underpinning the exercise of credit, that regard wider interests:

- the interests of savers, who supply the bank's primary resources, whose orientation is fundamental for the development of the banking and economic system generally, during both the collection and management of savings;

- the interests of investors, whether private individuals, firms and other entities;

- the interests of competitors, regarding the recourse and collaboration of other banks, with reference to inter-company operations based on copartnership or support to the system;

- the interests of the watchdog authorities monitoring respect of standards and the protection of interested parties;

- the interests of the financial and public authorities, on the basis of the contribution they make to the relationship between the different parties;

- the interests of foundations, associations and other non-profit agencies, that receive contributions, intervention and donations from the banks;

- the interests of the community and the territory, because it is limited locally, for employment, culture and development of the population and the environmental context; because it is extended to the community and to the national and global territory, for cooperation and general economic development.

There can be no doubt that focusing attention on banks' responsibility is significant on two main fronts: that of the collection and management of savings, which, because of its distinctive characteristics is subject to constraints and regulations; and that of the allocation of resources received from savers, which emphasises the size of commitments and loans to businesses, families, etc., and which attracts the supervision and protection envisaged at a European and a national level.

The need to combine the economic-productive aspect of banks with the social aspect of their response to expectations of economic and civil growth in their environment, is demonstrated not only by the intervention undertaken in various educational, cultural and environment sectors, providing social and economic support to the development of smaller companies, but also by the information communicated by the social report. 
Businesses and banks play an increasingly interconnected role in terms of investment in risk capital and loan capital and in terms of its influence in the governance structure. Bonds which, in transparent and correct relationships, may be profitable for the maintenance and development of conditions of economy, durability and autonomy for both parties, provided this is also to the advantage of the other stakeholders (employees, savers, investors, general public, etc.).

To conclude, recalling the activity of providing credit to businesses, we can state that banks' responsibility in the decision to award credit to each individual company implies both a detailed assessment that does not exclude risk, and a correlation with the responsibility taken by the company in relation to the bank and involved third parties, which extends and underpins both opportunities and growing risks in the new competitive scenario.

\section{Bibliography}

Anderson J., Narus J., Business Market Management, Prentice Hall, $2^{\text {nd }}$ ed., 2004.

Banca d'Italia Financial Sector Pro-Cyclicality, Lesson from the Crisis, April 2009.

Bastia P., Il sistema di controllo interno nella governance delle imprese italiane, Salvioni D.M. (ed.), Corporate Governance e sistemi di controllo della gestione aziendale, FrancoAngeli, Milan, 2004.

Beretta S., Valutazione dei rischi e controllo interno, Egea, Milan, 2004.

Bertini G., Introduzione allo studio dei rischi nell'economia aziendale, Giuffrè, Milan, 1987.

Brondoni S.M., Market-Driven Management, Concorrenza e Mercati Globali, Giappichelli, Turin, 2007.

Chevalier A., Le risk management: pour une meilleure maitrise des risques de l'entreprise, Entreprise moderne d'édition, Paris, 1982.

Day George S., Market Driven Winners, Symphonya. Emerging Issues in Management (symphonya.unimib.it), n. 2, 2000-2001.

http://dx.doi.org/10.4468/2001.2.02day

Doherty N.A., Corporate Risk Management: a Financial Exposition, McGraw-Hill, New York, 1985.

European Commission, How to Deal with the New Rating Culture, 2005.

European Commission, European Commission's Green Book, 2001.

Forestieri M., Risk Management. Strumenti e politiche per la gestione dei rischi puri dell'impresa, Egea, Milan, 2000.

Gandini G., Internal Auditing e gestione dei rischi nel governo aziendale, FrancoAngeli, Milan, 2004.

Green Book, Promoting a European Framework for Corporate Social Responsibility, EC, Brussels, 2001.

Mazzoleni A., Controllo di gestione e performance aziendali nelle PMI, FrancoAngeli, Milan, 2008.

Oriani M., I rapporti tra banche e piccole imprese, CRIF, Milan, 2008.

Perrotti G.P., Cassano R., Il ruolo dei confidi, Gandini G. (ed.), Governo d'impresa e orientamento competitivo al mercato bancario, FrancoAngeli, Milan, 2008. 
Readhead K., Financial Risk Management, Aldershot, Gower, 1988.

Salvioni D.M. (ed.), Corporate Governance, controllo e trasparenza, FrancoAngeli, Milan, 2007.

Wheeler D., Davies R. Rachel, Gaining Goodwill: Developing Stakeholder Approaches to Corporate Governance, Journal of General Management, vol. 30, n. 2, 2004.

\section{Notes}

${ }^{1}$ In particular there were evident risks related to the indiscriminate financing of the real estate market by US banks which, in a period of global recession, have provoked serious tension on productivity and a widespread reduction of liquidity. As a consequence, the difficulties of businesses have worsened, with increased dismissals and unemployment, falling living conditions for the general public, a contraction in consumption, growing insolvency and indebtedness of banks, with inevitable repercussions for the entire interbank system as the crisis spreads all over the world.

${ }^{2}$ Cf. J. Anderson, J. Narus, Business Market Management, Prentice Hall, $2^{\text {nd }}$ ed., 2004.

${ }^{3}$ Cf. George S. Day, Market Driven Winners, Symphonya. Emerging Issues in Management (symphonya.unimib.it), n. 2, 2000-2001. The above sense includes the chosen orientation of economic activities and credit negotiation which must not be based on mere speculation linked to market trends, whether for the production of goods and services or of capital, but on a sound evaluation of the possibilities for sustainable development and maintenance of a suitable economic level, for all stakeholders.

${ }^{4}$ Cf. S.M. Brondoni, Market-Driven Management Concorrenza e Mercati Globali, Giappichelli, Turin, 2007, p. XIV.

${ }^{5}$ Regarding risk configuration we refer you to, among others: Bertini G., Introduzione allo studio dei rischi nell'economia aziendale, Giuffrè, Milan, 1987; Forestieri M., Risk Management. Strumenti e politiche per la gestione dei rischi puri dell'impresa, Egea, Milan, 2000; Beretta S., Valutazione dei rischi e controllo interno, Egea, Milan, 2004; Gandini G., Internal Auditing e gesione dei rischi nel governo aziendale, FrancoAngeli, Milan, 2004.

6 A recent study by Banca d'Italia entitled 'Financial sector pro-cyclicality, Lesson from the crisis', April 2009, reveals that the rules for the determination of the minimum capital requirements rely on contingent elements that induce banks to rigidly apply the Basel 2 criteria in critical periods of high risk, contracting credit and the rising cost of loans. On the other hand, while respecting the principle of healthy and prudent management, it would be advisable to try to introduce a financial lever, facilitating credit to businesses that create added value.

${ }^{7}$ The crisis in the American banking system and the repercussions for other banking systems and for relations between them, even with reference to the market of credit to businesses, is one type of external risk that cannot be predicted easily, which increases other related risks such as the reduction in credit to business, the lack of liquidity and overall distrust of the system.

${ }^{8}$ Risk management emerges, in its basic structure, as a corporate sub-system on which the control system is projected and constantly interacts, in a logic that draws together different but constantly intertwined aspects. This is evident when one thinks of the need to monitor risks threatening a business and, at the same time, it is important to avoid the risk that a business faces if it does not implement an effective control system.

In the context of risk management monitoring, the following outline is proposed by Bastia P., Il sistema di controllo interno nella governance delle imprese italiane, in Salvioni D.M. (ed. by), Corporate governance e sistemi di controllo della gestione aziendale, FrancoAngeli, Milan, 2004, p. 86:

- global risk management (GRM), which regards the assessment of strategic risks;

- market risk management (MRM), which assesses the risk of exposure on the markets;

- credit risk management (CRM), which regards risks related to the collection of receivables;

- operational risk management (ORM), regarding analysis of operational risks; 
- regulatory risk management (RRM), which analyses the risk related to the violation of standards and regulations;

- risk system development (RSD), which regards a particular aspect of risk management linked to the development of support procedures and models.

Cf. Doherty N.A., Corporate Risk Management: A Financial Exposition, McGraw-Hill, New York, 1985; Readhead K., Financial Risk Management, Aldershot, Gower, 1988; Chevalier A., Le risk management: pour une meilleure maitrise des risques de l'entreprise, Entreprise moderne d'édition, Paris, 1982.

${ }^{9}$ In the global system of manufacture-sale of goods/services, the philosophy of market-driven management envisages that the company should focus on the competition (market-space) to identify temporary demand opportunities (demand bubbles) depending on the dominant position, and then choose the product characteristics that come closest to meeting expectations, in order to prepare contingent (but strong) differential advantages of supply (competitive pricing, before and better than competitors). Cf. Brondoni S.M., Market-Driven Management ed economia d'impresa globale e Market-Driven Management: prima e meglio dei competitor, in Brondoni S.M. (ed.), Market-Driven Management e mercati globali, Giappichelli, Turin, 2007.

${ }^{10}$ The collapse of financial products defined as 'derivative', associated to the globalisation of the banking sector, has created not only control difficulties, but actual crises in some cases, which have magnified in time and in space the effects of the loss of capital investments in highly risky enterprise (such as, for example, leveraged buyouts financed by a number of banks). For example, private equity represents an innovative financial tool and it comprises closed-end funds that originate in part from capital originally provided exclusively by wealthy individuals or very sound institutions, like investment banks, or even by special divisions of large commercial banks, and in part from capital originating from indebtedness, in all its forms, which range from traditional secured loans, to the issue of high yield bonds, mortgages and short-term bridging loans granted massively by banks. Hedge funds are also indicated as alternative investment tools, speculative funds, funds of funds, always opposed to the traditional forms of savings management, regulated by specific laws and regulations that limit their operativeness and risk. The term 'hedge' also means cover or protection; these investment funds, managed by special companies, are born in order to obtain positive operating results regardless of trends on the financial markets in which they operate.

${ }^{11}$ We refer you to the model proposed in Wheeler D., Davies R. Rachel, Gaining Goodwill: Developing Stakeholder Approaches to Corporate Governance, Journal of General Management, vol. 30, n. 2, 2004.

12 The claim becomes increasingly significant for small and medium enterprises that have no obligations in terms of communication and reporting, and should act on a voluntary basis to impart information about the size and characteristics of the governance model adopted, with particular regard for the active involvement of stakeholders and/or cooperation or partnership where it regards sectors that adopt integrated product policies (IPP). Cf. Green Book, Promoting a European framework for corporate social responsibility, EC, Brussels, 2001, which states that "IPP is founded on the consideration of product's impacts throughout their life cycle, and involves businesses and other stakeholders in dialogue to find the most cost-effective approach".

13 The latest generation of investment banks, using the financial instruments mentioned above, operates by investing in industrial conversion, in high risk entrepreneurial activities, in innovative sectors (even including the art industry) and seem to be in a situation of overexposure.

14 The corporate governance system envisages an organic combination of decisional and control structures, rules (codes of conduct, standards and regulations), and relations with the outside world (corporate responsibility).

15 The data quoted, taken from a 2004 ISTAT census of the juridical nature of SMEs, show private firms at $65 \%$ and partnerships at $22 \%$; research into the implementation of management control in SMEs in a specific territorial area reveal that little more than half of them adopt this system (Cf. Mazzoleni A., Controllo di gestione e performance aziendali nelle PMI, FrancoAngeli, Milan, 
2008); Assonime data for 2008 regarding the adoption by SMEs of the model of organisation and control, to comply with Leg. Decree 231/2001, reveal that only $27 \%$ of the businesses do so.

${ }^{16}$ A study conducted by Oriani M. with CRIF (a company specialising in credit information systems, business information and decision-making support), 'I rapporti tra banche e piccole imprese', Milan, 2008, shows that although 53.2\% of SMEs have conducted operations and investments suitable to improve the rating, fewer than $30 \%$ of them declare that they have undertaken adaptation operations rather than change, designed primarily to provide more information and reports, checking liquidity and improving the organisation (6.6\%).

17 The European Commission has defined SMEs as the backbone of the European economy, as demonstrated by a research published by the Commission itself, which shows that in the entire territory there are approximately 23 million active small and medium enterprises, equal to about 99\% of European companies. The operating guide is published by the European Commission, How to deal with the new rating culture, 2005.

${ }^{18}$ We refer you to Perrotti G.P., Cassano R., Il ruolo dei confidi, appendix 2 in Gandini G., Governo d'impresa e orientamento competitivo al mercato bancario, FrancoAngeli, Milan, 2008.

${ }^{19}$ It is now commonplace to use the term 'social responsibility', which was first used extensively in the 1980s in the USA by Edward Freeman, who states that Corporate Social Responsibility, or CSR, refers to the integration of ethical concerns within a corporate strategic vision. It is a manifestation of the will of large, small and medium enterprises of all types to effectively deal with issues of social and ethical impact within them and in their areas of activity. He introduces the theory of stakeholders and of balancing the interests of all those who have relations inside and outside the company. Extending these concepts to Europe, in the European Commission's Green Book of 2001, CSR was defined as "a concept whereby companies integrate social and environmental concerns in their business operations and in their interaction with their stakeholders on a voluntary basis". The document states that being socially responsible means "not only fulfilling legal expexctatios, but also going beyond compliance and investing 'more' into human capital, the environment and the relations with stakeholders." In Italy, to quote a few illustrious authors, corporate doctrine began to concern itself with social responsibility, initially with its founder Gino Zappa in about the 1950s, affirming a firm's social function, and then with Carlo Masini who, in the 1960s, defined a firm as an economic and social cell, and underlined the ethical responsibility linked to governance of the firm. A series of studies gradually brought the phenomenon of CSR to the public's attention, partly as an effect of the changes occurring, such as: the globalisation of the markets, communication and knowledge; consumerism, or the protection of consumer rights; the defence of the environment and future sustainability; the evolution of a corporate culture. This made it necessary to define the connotations of CSR more closely, making it equally important to understand what CSR is not:

- CSR is not a social commitment, which represents a residual part of a much vaster responsibility than something that is a façade or 'image' operation, and must therefore take a much more substantial form;

- CSR cannot be the pursuit of a mere competitive advantage, in other words a simple marketing operation.

Acting on the basis of CSR means setting up a governance organ and permeating the entire process that starts from the acquisition of the resources, permeates the performance of all activities and is reflected in results in order to obtain the consensus of all the internal and external partners and to activate the virtuous circle that generates and adds value for all those with an interest in the company.

Social responsibility is expressed in the various corporate contexts that range from manufacturing companies to commercial and service companies, in particular banks, public authorities, and nonprofit organisations, because the attention of all stakeholders is concentrated on the integrity and transparency of the activities of each type of business. Integrity and reputation depend on the capacity to respond correctly and to prioritise and protect the interests of the different categories of stakeholders, stockholders, employees, customers or users, suppliers, financiers, savers, the Tax authorities, competitors, the general public and the environment.

${ }^{20}$ Cf. Salvioni D.M. (ed.), Corporate Governance, controllo e trasparenza, FrancoAngeli, Milan, 2007, p. 37, which states that significant players are "those who establish relations with the firm that 
can influence the evolution of core activities, to obtain a grant of financial resources as risk capital or credit, services rendered, supplies of goods and services, the acquisition of manufacturing results, the transfer of particular risk, tax payable, environmental impact and any other relationship that can be associated to the normal evolution of the system of economic events. This group, made up of interlocutors whom we might define as 'corporate players in the strictest sense', influences governance in economic, social, competitive and environmental terms. Players who might benefit from corporate results free of charge for an exclusive decision to donate part of the value created, are excluded."

${ }^{21}$ Cf. Gandini G., Internal Auditing e gestione dei rischi nel governo aziendale, FrancoAngeli, Milan, 2004, p. 139. 